\title{
EVALUATION OF BIPHASIC CALCIUM PHOSPHATE AND HYALURONIC ACID ON BONE REGENERATION IN TIBIA OF RATS (HISTOLOGICAL STUDY)
}

\author{
Ahmed S Abd elaziz*, Hany A Sherif**, Mohamed M Ali***
}

\begin{abstract}
Objective: The aim of this study was to evaluate histologically the effect of the Biphasic Calcium Phosphate and Hyaluronic Acid on bone regeneration in critical sized defects in tibia of rats. Materials and methods: The experimental part was carried out on 16 adult male albino rats and their weight almost $250 \mathrm{gm}$., the animals were grouped into 2 equal groups as the following; group I (control) which had not receive any thing, group II (experimental) which had received Biphasic calcium phosphate plus Hyaluronic acid (BCP+HyA). Specimens were harvested on days 7 and 28 after surgical procedures, prepared and examined histologically by H\&E stain, there were wide histological differences between the groups of this study along the different intervals of the study. Results: The histological results demonstrated that there was obvious retardation in granulation tissue formation, organization and bone formation in the control group I than the other group along the different intervals of this study. Moreover, there was great acceleration in granulation tissue formation, organization and bone formation in experimental group II which received the $(\mathrm{BCP}+\mathrm{HyA})$. this enhancement in bone healing process was due to the effect of $\mathrm{HyA}$ as it accelerates the bone regeneration by means of cell adhesion, chemotaxis, proliferation and successive differentiation of mesenchymal cells.
\end{abstract}

\section{INTRODUCTION}

Various graft materials have been developed and used for reconstruction of bony defects. Bone grafts fall into four general categories: autografts, allografts, xenografts, and alloplasts. ${ }^{(1)}$ The role of these materials in regenerative procedures is based on osteogenic potentiality (contain boneforming cells), osteoinductivaty (contain bone inducing substances), and osteoconductivaty (serve as a scaffold for bone formation) (2). Autograft and allograft remain the most effective grafting materials because they have more potentials for bone regeneration ${ }^{(3)}$. However, alternatives such as alloplast have been used because of donor site morbidity, limited supply, with increased cost of autografts and risk of disease transmission and response rejection by allografts ${ }^{(2)}$.An alloplast is a synthetic or inert foreign body material that has ostoeconductive capacity and can be produced in unlimited quantities without risk of disease transmission ${ }^{(4)}$. One of Currently used allopasts is biphasic calcium phosphate ${ }^{(1,4)}$.

Biphasic calcium phosphate (BCP) bioceramics belong to a group of bone substitute biomaterials that consist of an intimate mixture of hydroxyapatite (HA) $\left\{\mathrm{Ca}{ }_{10}\left(\mathrm{PO}_{4}\right)_{6}(\mathrm{OH})_{2}\right\}$ and beta-tricalcium phosphate $(\beta-\mathrm{TCP})\left\{\mathrm{Ca}_{3}\left(\mathrm{PO}_{4}\right)_{2}\right\}$ of varying $\mathrm{HA} / \beta$ TCP ratios. It is considered to be a more efficient ceramic material and an ideal bone substitute due to its favorable biological properties such as having high bioresorption rate, microporosity, compressive strength, bioreactivity, dissolution, and

\footnotetext{
*Demonstrator, Oral Biology Department, Faculty of Dental Medicine, Al-Azhar University, Boys, Cairo

***Professor, Oral Biology Department, Faculty of Dental Medicine, Al-Azhar University, Boys, Cairo

***Lecturer, Oral Biology Department, Faculty of Dental Medicine, Al-Azhar University, Boys, Cairo
} 
osteoconductivaty ${ }^{(5)}$. It's used in extraction socket, sinus lifting, ridge augmentation and bone defects ${ }^{(6)}$. Although BCP graft is commonly used as bone substitutes, numerous studies have reported that grafted BCPs did not increase bone formation ${ }^{(7)}$.

Hyaluronic acid (HyA, also known as hyaluronan or hyaluronate) was first discovered and isolated from the vitreous body of cows' eyes by Karl Meyer and John Palmer in1934 ${ }^{(8)}$. The proposed name "hyaluronic acid" was derived from "hyalos," meaning glass in Greek word. Hyaluronic acid is a naturally-derived polymers and considered as a major component of the extra cellular matrix which presents in nearly every mammalian tissues and fluid $^{(9)}$. Hyaluronic acid (HyA) has osteoconductive potentiality as it accelerates the bone regeneration by means of cell adhesion, chemotaxis, proliferation and successive differentiation of mesenchymal cells. HyA may act as biomaterial scaffold for other molecules, such as BMP- 2 and TGF- $\beta$, used in guided bone regeneration techniques and tissue engineering research ${ }^{(10)}$. HyA exhibits biophysical properties of high viscosity, elasticity, and negative charge. It also shows bacteriostatic ${ }^{(11)}$, fungistatic $^{(12)}$, anti-inflammatory ${ }^{(13)}$, anti-edematous ${ }^{(14)}$, osteoinductive $^{(15)}$ and proangiogenetic characteristics. ${ }^{(16)}$ Up to now, HyA has mostly applied for bone formation of craniofacial bone defect and dental applications in various animal models ${ }^{(17)}$.

So, in the present study we examine the effect of HyA with biphasic calcium phosphate on bone regeneration using histological investigations.

\section{MATERIALS AND METHODS}

This study was carried out on sixteen adult male albino rats, their average weight was about $250 \mathrm{gm}$. The procedure management was carried out at house animals of Faculty of medicine, Cairo University.

\section{Grouping and experimental planning}

The animals were divided randomly into two main groups as follows:
Group (I), control group consisted of eight rats which had not receive any thing.

Group (II), experimental group consisted of eight rats which had received the $(\mathrm{BCP}+\mathrm{HyA})$.

\section{RESULTS}

At seven days intervals of control group (I) demonstrated that the center of the defect was filled with blood clot which infiltrated by inflammatory cells, mainly mononuclear leucocytes and macrophages. At the Surface of the defect profuse inflammatory cell infiltration were observed, whereas at the base of the defect there was early formation of granulation tissue and proliferating blood capillaries. (fig.1).

28 days interval of control group demonstrated that at the surface of the defect there was thin rim of well-organized granulation tissues which characterized by tightly packed collagen bundles and recruitment of osteoblasts. The center of the defect was filled with thin irregular trabeculae of woven bone. The trabeculae of the newly formed bone were lined by osteogenic cells and osteoblasts. Also, there were wide marrow sinusoidal heamopiotic cavities in between them which filled with heamopiotic tissues. (fig.2).

Seven days interval of experimental group (BCP+HyA) (II) demonstrated that the center of the defect was filled with remnant of $\mathrm{BCP}+\mathrm{HyA}$. Underneath the $\mathrm{BCP}+\mathrm{HyA}$ there were well organized granulation tissues which characterized by more condensed, tightly packed collagen bundles interspersed by fibroblasts and proliferating blood capillaries. There was recruitment of osteoblasts observed within the granulation tissue. There were sequestrated bone chips observed within the granulation tissue and surrounded by osteoclasts. At the base and sides of the defect there were new bone trabeculae formation which coalescent with each other and enclosing marrow spaces with irregular diameter and containing heamopiotic tissues. 
There were early imprisoned osteoblasts within the bone matrix of the newly formed bone forming osteocytes with wide osteocytic spaces. The side of the defect demonstrated well demarcated scalloped reversal line. (Fig.3)

28 days interval of) $\mathrm{BCP}+\mathrm{HyA}$ ) showed the defect was closed by bridge of bone which connected to old bone. The base of the defect was completely

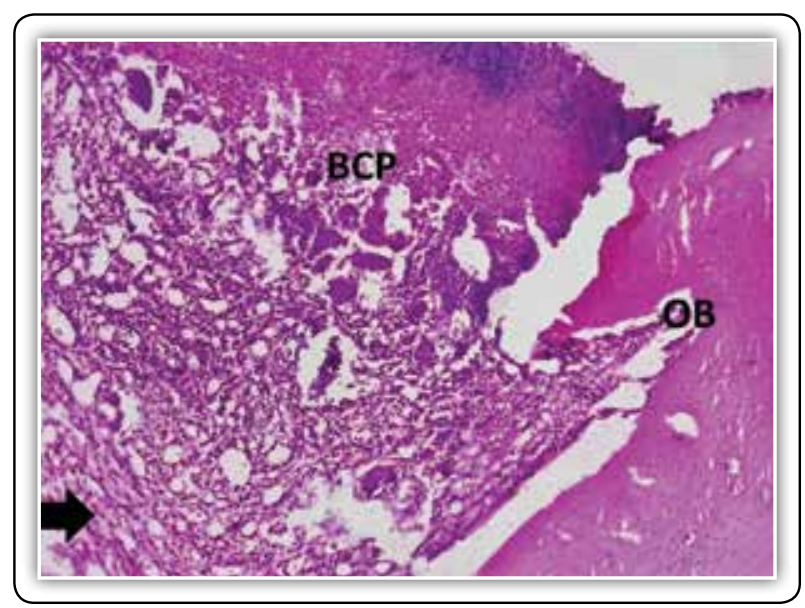

FIG (1) Histological section of control group at 7 days intervals showing remnant of blood clot $(\mathrm{BC})$, granulation tissue (thick arrow), and old cortical bone (OB) H\&E(Mag.100x).

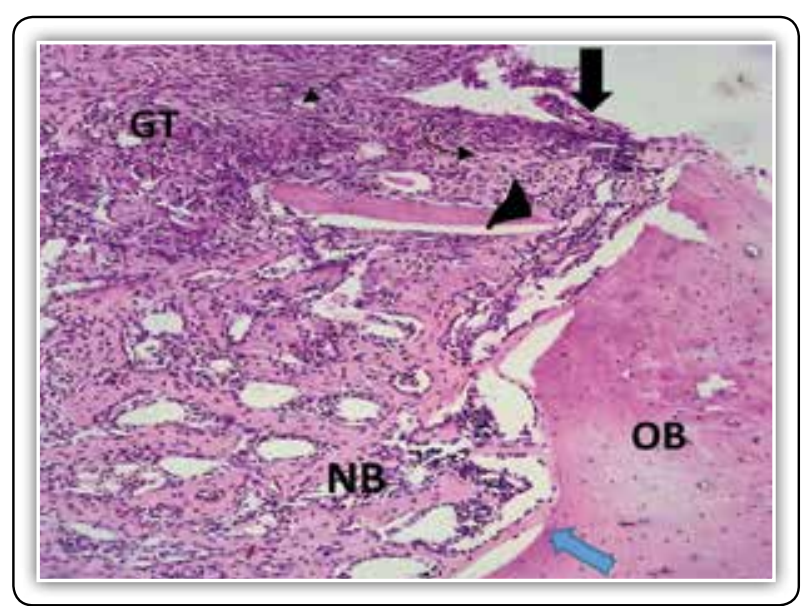

FIG (3) Histological section of (BCP+HyA) group at 7 days intervals showing remnant of $\mathrm{BCP}+\mathrm{HyA}$ (thick arrow), new bone (NB), well organized granulation tissue (GT), blood vessel (thin arrow), sequestrum (arrow head), recurrent of osteoblast (curved arrow), reversal line(blue arrow) and old cortical bone(OB) H\&E (Mag.100x). filled with new bone which formed of thick bone trabeculae. These trabeculae were coalescent and anastomosed with each other forming trabecular network and were connected to the old bone. The bone trabeculae were harboring multiple marrow cavities in between them which filled with heamopiotic tissue and lined by osteogenic cells and osteoblasts. There was a reversal line demarcating the old bone from the newly formed bone. (Fig.4).

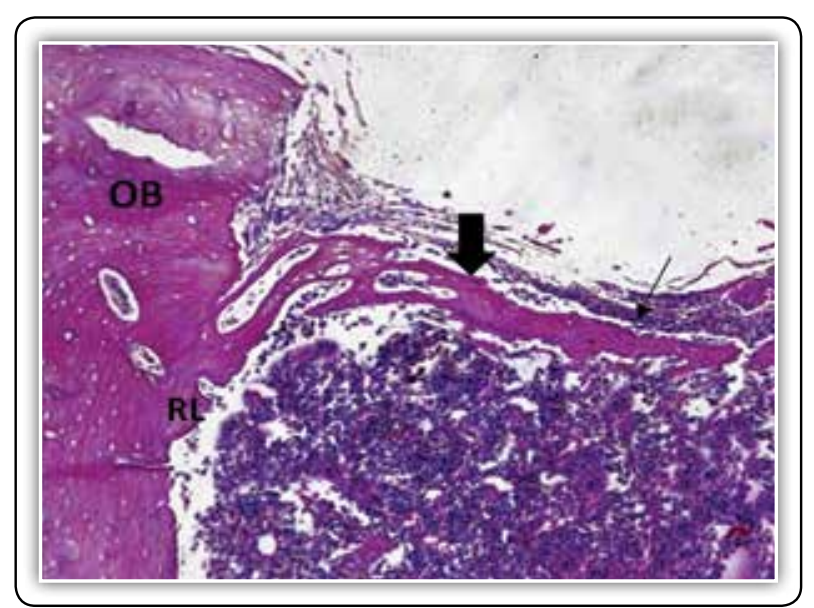

FIG (2) Histological section of control group at 28 days intervals showing thin rim of granulation tissue (thin arrow), thin irregular trabeculae of woven bone (thick arrow), reversal line (RL) and old bone (OB). H\&E (Mag.100x).

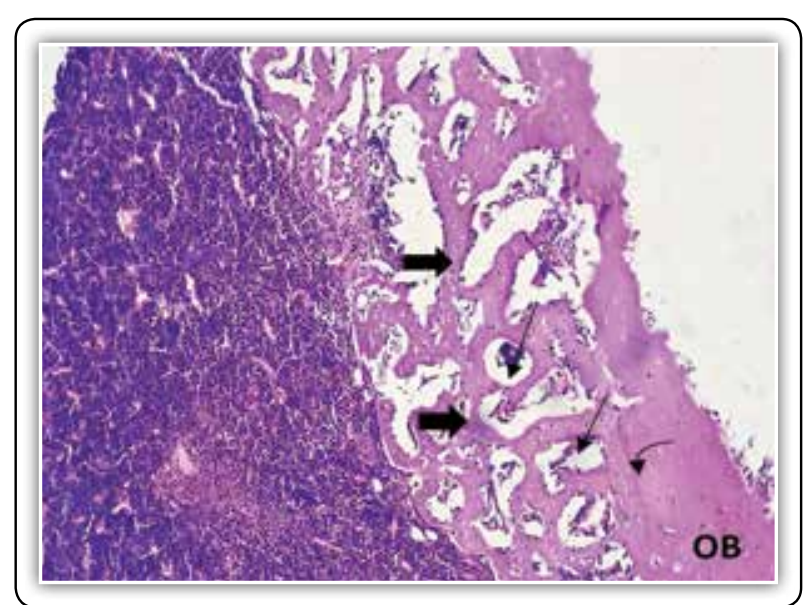

FIG (4) Histological section of (BCP+HyA) at 28 days showing thick trabeculae of bone (thick arrow), marrow space (thin arrow), old bone (OB) and reversal line (curved arrow). H\&E. (Mag. 100x) 


\section{DISCUSSION}

Bone healing is a very remarkable process resulting in regeneration of the anatomy of bone and complete return to function. Bone injury typically associated with disruption of the local tissue integrity, interruption to normal vascular function, and distortion of the marrow architecture.

Biphasic Calcium phosphate has been selected for this study as a one of the most commonly used alloplasts and because of its biocompatibility, handling characteristics, porosity, chemical and physical resemblance to bone minerals and potentially unlimited supply at a low price $^{(18,19) \text {. }}$

Studies demonstrated that HyA promote bone formation and accelerated bone regeneration by means of chemotaxis, proliferation and successive differentiation of mesenchymal cells ${ }^{(11)}$. It significantly increased alkaline phosphatase and hence stimulate cell mineralization ${ }^{(20)}$. HyA allowed the early deposition of osteoid tissue by providing a scaffold on which osteoprogenitor cell attached and so stimulated osteoblastic differentiation.

At seven days interval $\mathrm{n}$ the control group the bone defect was filled with blood clot which still replaced by early formation of granulation tissues. The collagen bundles were interspersed by fibroblasts and blood vessels. These finding were in agreement with Solheim E. 1998, (21) Bruder SP and Fink DJ. 1994, ${ }^{(22)}$ who stated that the clot is replaced by granulation tissue by cellular mobilization and vascular in growth with extensive neo-angiogenesis.

Moreover, the group treated with $\mathrm{BCP}+\mathrm{HyA}$ demonstrated that there were new bone trabeculae formation which coalescent with each other and enclosing marrow spaces with irregular diameter and containing heamopiotic tissues. This finding was coincidental with the results of Bansal $\mathbf{J}$ et al ${ }^{(10)}$ who stated that Hyaluronic acid (HyA) has osteoconductive potentiality; it accelerates the bone regeneration by means of chemotaxis, proliferation and successive differentiation of mesenchymal cells. HyA may act as biomaterial scaffold.

On the basis of the present study we observed from the different histological findings between these groups at seven days interval that more bone regeneration and acceleration in healing in $(\mathrm{BCP}+\mathrm{HyA})$ than control group.

The current work in the control group at 28 days interval revealed at the surface of the defect there was thin rim of well-organized granulation tissues. The center of the defect was filled with thin irregular trabeculae of woven bone. While in the group treated with $(\mathrm{HyA}+\mathrm{BCP})$ showed that the defect was completely filled with bone which formed of thick bone trabeculae. These finding were in agreement with Nguyen and Lee ${ }^{(23)}$ who revealed enhanced bone regeneration and cell proliferation around $\mathrm{BCP}+\mathrm{HyA}$ gel material.

On the basis of the current study we observed from the different histological findings between these groups at twenty eight days interval that the best bone regeneration in $(\mathrm{BCP}+\mathrm{HyA})$ followed by control group and such observation was confirmed by Aslan et $\mathbf{a l}^{(24)}$ stated that bone formation in noncritical-size tibial defects filled with HyA with an allogenic cancellous bone graft was higher than that in defects filled with the allogenic cancellous bone graft alone and control group at the late stage of healing.

\section{CONCLUSION}

1. The combination of hydroxyapatite and beta-tricalcium phosphate could contribute to inducing both higher porosity and larger specific surface area, and it is considered that these both factors played a significantly role in the remarkable bone regeneration effects.

2. BCP has been shown to have good biocompatibility and osteoconductivaty and can be used to enhance bone healing specially.

3. HyA promote bone formation and accelerated bone regeneration. 


\section{REFERENCES}

1. Bashutski JM, Wang H. Periodontal and endodontic regeneration. J Endod 2009; 35:321-8.

2. McAllister BS, Haghighat K. Bone augmentation techniques. J Periodontol 2007; 78:377e96.

3. Gazdag AR, Lane JM, Glaser D, Forster RA. Alternatives to autogenous bone graft: efficacy and indications. J Am Acad Orthop Surg 1995; 3:1e8.

4. Krishnamurithy G. Areview on hydroxyapatite-based scaffold scaffolds as a potential bone graft substitute for engineering applications. JUMMEC 2013; 16:1e6.

5. Sun L., Wu L., Bao C., Fu C. Gene expressions of Collagen type I, ALP and BMP-4 in osteo-inductive BCP implants show similar pattern to that of natural healing bones Mater Sci Eng C 29, 1829, 2009.

6. Daculsi G, Passuti N, Martin S, Deudon C, Legeros RZ, Raher S. Macroporous calcium phosphate ceramic for long bone surgery in humans and dogs. Clinical and histological study. J Biomed Mater Res. 1990;24(3):379-96.

7. Park JC LH, Sohn JY, Yun JH, Jung UW. "Bone regeneration capacity of two different macroporous biphasic calcium materials in rabbit calvarial defect., J Korean Acad Periodontol. 2009; 39:223-30.

8. Fakhari A, Berkland C. Applications and emerging trends of hyaluronic acid in tissue engineering, as a dermal filler and in osteoarthritis treatment. Acta Biomater 2013; 9:7081-7092.

9. Zheng Shu X, Liu Y, Palumbo FS, Luo Y. In situ cross linkable hyaluronan hydrogels for tissue engineering. Biomaterials 2004; 25:1339-1348.

10. Bansal J, Kedige SD, Anand S. Hyaluronic acid: A promising mediator for periodontal regeneration". Indian J Den Res 2010; 21(4): 575-8

11. Carlson GA, Dragoo JL, Samimi B, Bruckner DA. Bacteriostatic properties of biomatrices against common orthopaedic pathogens. Biochem Biophys Res Commun 2004; 321:472-478

12. Kang JH, Kim YY, Chang JY, Kho HS. Influences of hyal- uronic acid on the anticandidal activities of lysozyme and the peroxidase system. Oral Dis 2011; 17:577-583.

13. Turley EA, Noble PW, Bourguignon LY. Signaling properties of hyaluronan receptors. J Biol Chem 2002; 277:4589-4592.

14. Dahiya P, Kamal R. Hyaluronic acid: A boon in periodontal therapy. N Am J Med Sci 2013; 5:309-315.

15. Sasaki T, Watanabe C. Stimulation of osteoinduction in bone wound healing by high-molecular hyaluronic acid. Bone 1995; 16:9-15.

16. Raines AL, Sunwoo M, Gertzman AA, Thacker K. Hyaluronic acid stimulates neovascularization during the regeneration of bone marrow after ablation. J Biomed Mater Res A 2011; 96:575-583.

17. Bae MS, Yang DH, Lee JB, Heo DN, Kwon YD, Youn IC, et al. Photo-cured hyaluronic acid- Based hydrogels containing simvastatin as a bone tissue regeneration scaffold. Biomaterials 2011; 32:8161-8171.

18. Bruder SP. and Fink D Caplan AI. Mesenchymal stem cells in bone development, bone repair and skeletal regeneration therapy. J Cell Biochem 1994; 56:283-294

19. Caplan AI. Bone development and repair. Bioassay1987; 6:171-175.

20. Taichman RS. Blood and bone: two tissues whose fates are intertwined to create the hematopoietic stem cell niche. Blood.2005; 105:2631- 2639.

21. Solheim E. Growth factors in bone. Int Orthop 1998; 22:410-416

22. Bruder SP. and Fink D Caplan AI. Mesenchymal stem cells in bone development, bone repair and skeletal regeneration therapy. J Cell Biochem 1994; 56:283-294

23. Nguyen TBL, Lee BT. A combination of biphasic calcium phosphate scaffold with hyaluronic acid-gelatin hydrogel as a new tool for bone regeneration. Tissue Eng Part A 2014; 20:1993-2004.

24. Aslan M, Simsek G, Dayi E. The effect of hyaluronic acid supplemented bone graft in bone healing: experimental study in rabbits. J Biomater Appl 2006; 20:209-220. 